УДК 811.161 .1

DOI 10.52575/2712-7451-2021-40-2-264-270

\title{
Русские частицы и субъективная модализация информации
}

\author{
Нагорный И.А. \\ Цзилиньский университет \\ Китайская Народная Республика, 130012, г. Чанчунь, ул. Цянцзинь, д. 10 \\ Email: ignago7@outlook.com
}

\begin{abstract}
Аннотация. Проанализирован комплекс вопросов, отражающих параметры специфики коммуникативного функционирования русских частиц как субъективных модализаторов сообщаемого. Исследованы степени влияния частиц на смысловое поле высказывания, описаны коммуникативно обусловленные функции, выполняемые частицами при смысловом усложнении высказывания, его модализации. Выявлены и систематизированы функциональнокоммуникативные свойства частиц при выражении субъективной точки зрения говорящего на сообщаемое. Охарактеризованы коммуникативно-диалогические аспекты репрезентации ограничительными, усилительными, указательными, определительными, эмоциональными и модальными частицами русского языка модусных смыслов, прагматически обусловленных субъективно-авторским взглядом на действительность. Доказано, что русские смысловые частицы обладают коммуникативным статусом прагматико-речевых знаков, главные функции которых проявляются в модусно-квалификативной речевой зоне процесса коммуникации при актуализации особого модализованного типа семантических отношений говорящим.
\end{abstract}

Ключевые слова: функциональные параметры; функционально-коммуникативный подход; модализация информации; квалификационная репрезентация сообщаемого; русские частицы; функция речевого воздействия, адресатность.

Для цитирования: Нагорный И.А. 2021. Русские частицы и субъективная модализация информации. Вопросы журналистики, педагогики, языкознания, 40 (2): 264-270. DOI: $10.52575 / 2712-7451-2021-40-2-264-270$

\section{Russian particles and the subjective modalization of information}

\author{
Igor A. Nagornyy \\ Jilin University \\ 10 Qiangjin St, Changchun, 130012, People's Republic of China, \\ Email: ignago7@outlook.com
}

\begin{abstract}
The article analyzes a set of questions that reflect the parameters of the specificity of the communicative functioning of Russian particles as subjective modalizers of what is communicated. The study of the degrees of influence of particles on the semantic field of the utterance is carried out, the communicatively conditioned functions performed by the particles during the semantic complication of the utterance and its modalization are described. Revealed and systematized functional and communicative properties of particles when expressing the speaker's subjective point of view on what is reported. The communicative-dialogical aspects of representation are characterized by restrictive, reinforcing, indicative, determinative, emotional and modal particles of the Russian language of modus meanings, pragmatically conditioned by the author's subjective view of reality. It is proved that Russian semantic particles have the communicative status of pragmatic-speech signs, the main functions of which are manifested in the modulo-qualifying speech zone of the communication process when a special modalized type of semantic relations is actualized by the speaker.
\end{abstract}


Keywords: a functional parameters; functional-communicative approach; information modalization; qualification representation of the reported; Russian particles; speech influence function, addressability.

For citation: Nagornyy I.A. 2021. Russian particles and the subjective modalization of information. Issues in Journalism, Education, Linguistics, 40 (2): 264-270 (in Russian). DOI: 10.52575/2712-74512021-40-2-264-270

\section{Введение}

Проблема исследования принципов субъективной модализации сообщаемого представляется важной и своевременной в плане развития антропоцентрических, прагматических и функциональных идей современных лингвистических школ. Русская языковая система включает большое количество языковых средств и способов выражения говорящим своего личного мнения, оценки сообщаемого, производимой в самых различных аспектах. Русские частицы как выразители субъективного, авторского взгляда на действительность относятся, по нашему мнению, к весьма продуктивным и прагматически сориентированным языковым знакам модализации сообщаемого. Использование антропоцентрического и функционального подходов при исследовании модализационной роли русских частиц в процессе коммуникации может способствовать решению важных вопросов в области коммуникативистики и прагматики, уточнению критериев соотношения системноязыковой и речевой сфер русского языка, исследованию фактора антропоцентричности, детализации описания русской языковой и концептуальной картин мира.

Исходя из сказанного, целесообразным видится исследование не только собственно грамматических свойств русских частиц, но и их коммуникативных качеств, особенно ярко проявляющихся при модализации частицами сообщаемого, модусном корректировании смыслового поля предложения и текста. Анализ степеней влияния, оказываемого частицами на коммуникативный процесс, в частности на фактор адресата, также представляется важным в антропоцентрическом аспекте.

\section{Объекты и методы исследования}

Теоретический материал исследовался при помощи описательного, систематизационного и общедедуктивного методов, позволивших развить теоретическую базу работы относительно достижения поставленной цели и решения намеченных задач, что в результате дало возможность доказать выдвинутую гипотезу, положенную в основу научного описания, сделать теоретические выводы, наметить перспективы дальнейшей работы. Для анализа иллюстративно-текстового материала, кроме собственно описательного метода, были применены сравнительно-сопоставительный и функциональный методы, а также прием количественного подсчета, сориентированные на систематизацию теоретических и практических аспектов исследования, на многоаспектный функциональный анализ особенностей модализации сообщаемого русскими частицами в коммуникативной сфере. Выявление и описание функционально-текстовых характеристик русских частиц также опиралась на применение структурного метода.

\section{Результаты и их обсуждение}

Применение коммуникативного и функционального подходов к исследованию прагматически насыщенных речевых элементов помогает не только установить формально-грамматический статус отдельных элементов в общей системе языка, но и обосновать коммуникативно-прагматические характеристики языковых единиц, определить критерии функционирования данных языковых компонентов в составе высказывания, включенного в речевую диалогическую сферу. 
В указанном аспекте, на наш взгляд, оказывается интересным и продуктивным изучение коммуникативно-сориентированных речевых функций русских частиц как слов многофункциональных [Schwarz, Tiemann, 2017; Hans, 2019]. Данные языковые элементы ярко проявляют себя на уровне речевого общения, являются прагматически значимыми и семантически емкими.

Глубокое исследование языковых и в большей степени речевых функциональных свойств частиц преследует не только теоретическую, но и практическую цель - расширить пути осмысления проблем, актуализируемых функционально-коммуникативной лингвистикой [Колмогорова, 2016], прагмалингвистикой [Лакофф, 1988], социо- и этнолингвистикой [Перехвальская, 2020]. К указанным стоит отнести проблему антропоцентричности русских слов [Вольф, 2010], прагматически обусловленного речевого воздействия говорящего на адресата [Lakoff 1975; Винокур, 2016], коммуникативной сущности эмотивизации и экспрессивизации сообщаемого [Арутюнова и др., 1992; Катермина, 2015].

При углубленном изучении особенностей коммуникативного процесса все это оказывается закономерно связанным с необходимостью усвоения механизмов смыслового усложнения высказывания [Yu, 2017; Арутюнова, 2019], его модализации [Depraetere, 2015; Börjesson, 2016], в том числе при помощи частиц различных семантических групп, оказывающихся весьма продуктивным речевым инструментарием прагматического воздействия на адресата.

В аспекте функционально-коммуникативного анализа интересными представляются следующие семантические группы русских частиц:

1. Группа ограничительных частиц: «только», «лишь», «только лишь», «всегонавсего», «просто», «исключительно» и др. Уточняется, что такого рода русские частицы вводятся в высказывание субъектом для конкретизации и локализации собственной точки зрения на каком-либо фрагменте события. Конкретизация же субъективного мнения автора сообщения в ограничительном аспекте ожидаемо сужает семантическое пространстворечевого высказывания, на которое распространяется влияние русских ограничительных частиц: Это только к нему относится (Е. Носов); Всего-навсего одно поручение нужно выполнить (А. Толстой); А мечты осуществляются лишь частично (А. Иванов); Нам осталось только лишь решить, кто будет первым (Д. Донцова).

2. Группа усилительных смысловых частиц: «прямо», «просто», «еще», «даже», «положительно», «определенно». Такого рода языковые элементы в сфере коммуникации функционируют как языковые средства иллокутивного характера. Они усиливают личностное мнение субъекта, фиксируют его и тем самым прагматически концентрируют точку зрения говорящего на актуализируемом события или на его отдельной части: Отлично, что у нас появился ещё один шанс (Е. Гущин); -Мы двинемся туда прямо сейчас (Е. Симонов); Можно даже и не торопиться, мы уже опоздали (И. Ефремов); Просто я узнал об это раньше его (Д. Донцова).

3. Группа указательных частиц: «вон», «вот», «во», «это», «вот как» и др. Коммуникативные характеристики такого рода частиц русского языка локализованы в зоне демонстрации речевой позиции говорящего. В основном указанная локализация производится относительно какого-то частного эпизода события при одновременном усилении коммуникативной роли говорящего, который приглашает адресата присоединиться к нему в том или ином видении конкретной ситуации: Вон сколько у нас делов и забот образовалось. И это только начало (О. Баринов); Вот сад и сторожка (Е. Леонов); А это как вам угодно, дорогой мой товарищ (А. Толстой).

4. Группа определительных частиц, таких как «как раз», «именно», «приблизительно», «равно», «чуть не» и др. Особенности функционирования такого рода языковых средств в коммуникативной зоне сосредоточены на конкретизации озвучиваемого, определяемого автором сообщения как какое-либо уточнение: $A$ это как раз насчет вашего рацпредложения (М. Задорнов); Его, вероятно, тогда заинтересовало именно это сообщение (В. Распутин); Приблизительно так я это и понял (Ю. Семенов). 
5. Группа эмоциональных частиц: «что за», «даже», «ну и», «же», «куда», «куда уж», «эк», «ишь», «ведь», «как», «все», «все-таки», «где уж», «вот так». Данная группа частиц русского языка активно работает в речевой зоне коммуникации как средство эмотивизации и экспрессивизации прагматически сориентированной информации. Эмоциональные частицы активно помогают человеку ввести в свое речевое высказывание разного рода эмоции, сосредоточить внимание адресата на своих чувствах, который автор сообщения стремится выразить, дать яркую положительную/отрицательную оценку целого события или его фрагмента. Рассматриваемые частицы усиливают оценочный фактор сообщения, а при необходимости и экспрессивизируют его. Разнообразные человеческие эмоции - от восторга, восхищения, удивления, радости до грусти, разочарования, злобы, уныния - могут быть актуализированы в авторском высказывании как раз с помощью частиц эмоциональной группы. Часто выражение автором своих эмоций и составляет суть речевого сообщения. Поэтому генерация и донесение автором своих эмоций и чувств до адресата может расцениваться, как думается, в качестве ведущего мотива коммуникативного процесса, актуализируемого говорящим. Кроме этого, в коммуникативной сфере на экспликацию авторской оценки нередко наслаивается и дополнительная экспрессивизация автором сообщения своих эмоций, что, несомненно, усиливает выразительность речевого оценочного сообщения: Что за чудное событие произошло сегодня! (Д. Донцова); Как ты этого понять не можешь! Это очень сложно? (Д. Донцова); Вот так явление! А я и не ждал тебя (Е. Глушков); Ну и сльшу в ответ: -Да где ужс тебе! (С. Иванов).

6. Группа модальных частиц русского языка, включающая семантические подгруппы частиц:

- модально-сомнительные («едва ли», «вряд ли», «навряд ли»): - Неужели так? Едва ли (С. Лукьяненко); - Думаешь, все образуется? - Вряд ли, раньше нужно было реагировать (В. Плетнев); - Все-таки не поедешь на встречу? - Навряд ли (Ю. Семенов).

- модально-сравнительные («будто», «как будто», «точно», «словно бы», «вроде», «вроде как», «ровно»): - Собираешься дальше здесь находиться? -Как будто... (С. Иванов); Будто и не с нами это произошло (С. Лукьяненко).

- собственно предположительные («как бы», «чай», «небось», «авось», «никак», «что ли», «поди»): Чай, к нам, милок, пожаловал? (А. Островский); - Авось и не сбудется твоя печаль (Д. Донцова); - Да ты поди и не сльхал про ту историю? (В. Шукшин).

- модально-вопросительные («неужели», «разве», «неужто»): - Неужели так все и случилось? Не верю (М. Горький); - Ты разве не был в числе первых? (И. Ефремов); - Да неужсто так и было? (А. Иванов). - Это неслыханно! Неужели доскачешь? (А. Аверченко)

- модально-эвиденциальные частицы («дескать», «мол», «якобы», «де»): - А онхороший спец? -Ну якобы... (Ю. Семенов); Дескать не результат важен, а сам процесс. Интересно (Е. Гущин).

- модально-избыточные частицы («едва ли не», «вряд ли не», «чуть ли не»): Eкатерина чуть ли не самая эрудированная в классе (Журн. текст); И в результате этот человек двигался едва ли не мимо своей самой важной цели в жизни (Журн. текст);

Особенности функционирования указанных групп частиц на собственно системном уровне и в речевой сфере обусловлен видимым несоответствием их грамматического статуса в русской языковой системе как служебных элементов [Виноградов, 2001] и усиленным прагматико-коммуникативным статусом как продуктивного и семантически емкого компонента в речевом высказывании и шире - в речевом диалоге. Русские частицы как актуализаторы целого ряда авторских квалификативных модусных смыслов совмещают в своем функционально-смысловом поле формальную грамматикализованность своего частеречного значения, с одной стороны, и семантико-прагматическую емкость, обусловленную коммуникативной природой частицы, - с другой [Нагорный, 2019]. Установить 
причины, обусловливающие этот языково-речевой феномен русских частиц - одна из важнейших задач в перспективном функционально-коммуникативном анализе заявленных проблем, решение которых поможет глубже понять глубинные языковые процессы, отражающие как собственно языковые закономерности функционирования русских частиц, так и специфику русской языковой картины мира, рефлектировнной на уровне языковых средств - выразителей субъективного взгляда говорящего на действительность.

Будучи малофункциональными в формально-грамматическом плане, русские частицы по продуктивности своего функционирования в повседневной речевой сфере фиксируются на одном из лидирующих мест. Данные языковые элементы - весьма частотные речевые знаки [Шведова, 2003; Ван, Стародумова, 2018; Мелехова, Сергиевская, 2019; Ломтев, 2020; Отношение к..., 2020], имеющие сильную прагматическую составляющую в своем семантическом поле, которая и позволяет русской частице генерировать в речевой зоне комплекс доминирующих семантико-прагматических функций - в первую очередь функцию квалификативную (субъективная квалификация информации) и функцию прагматическую (речевое воздействие на адресата при помощи донесения до последнего точки зрения говорящего): - Не видели, что ли, как люди живут? (К. Паустовский); Прищуренные уголки её глаз чуть ли не ульббались (А. Толстой); - А у самого-то небось и душа в пятках? (С. Лукьяненко); Это было нечто вроде поучения потомкам (Журнальный текст); - Да разве шучу я в самом деле? (А. Островский);

Абсолютное большинство смысловых частиц русского языка необходимо, по нашему мнению, рассматривать как прагматико-речевые знаки, наиболее важные функции которых фиксируются именно в квалификативной речевой зоне процесса коммуникации актуализации и обозначении особого модусного типа семантических отношений с точки зрения оценивающего эти отношения человека. В русских речевых высказываниях с частицами субъективный (квалификативно-оценочный) и объективный (собственно событийный) слои смысла сближены, представляют неразрывное целое.

В целом, применение функционально-коммуникативного подхода при анализе частиц русского языка видится, на наш взгляд, продуктивным, так как помогает объяснению некоторых важных функционально-прагматических аспектов при изучении системной и речевой сфер русского языка, позволяет перенести исследуемые проблемы на антропоцентрическую языковую сферу, область русской языковой и концептуальной картины мира, помогает решить целый ряд вопросов коммуникативистики и функциональной прагматики.

\section{Заключение}

Подведем итог сказанному. Применение функционально-коммуникативного анализа частиц при установлении их функциональной нагрузки в процессе коммуникации, на наш взгляд, мотивировано тем, что слово в языково-речевой сфере фактически многофункционально. Многофункциональные языковые средства выполняют в речевой сфере человеческого общения комплекс функций, обусловленных смысловой и прагматической ролью слова, отведенной данному языковому средству говорящим в процессе коммуникативного обмена информацией. Учет фактора функциональной разноаспектности при анализе коммуникативных функций русского слова, по нашему мнению, закономерен и оправдан. В связи со сказанным крайне целесообразным представляется исследование не только традиционных (лексико-грамматических) параметров частиц русского языка, но ифункциональный анализ прагматизированных говорящим способов корректировки частицами общее смыслового поля речевого высказывания, а также того влияния, которое оказывается русскими частицами на коммуникативную сферу речевой реализации данного высказывания или комплекса высказываний. Это нужно учитывать, ибо взятые для исследования вопросы включаются в сферу антропоцентризма и прагматики. Актуализированные в статье проблемы видятся перспективным для своего развития в плане расширения границ функционального анализа русских частиц в антропоцентрическом аспекте. 


\section{Список литературы}

1. Арутюнова Н.Д., Булыгина Т.В., Кибрик А.А. 1992. Человеческий фактор в языке. Коммуникация, модальность, дейксис. Под ред. Т.В. Булыгиной. М., Наука, 280 с.

2. Арутюнова Н.Д. 2019. Предложение и его смысл. Логико-семантические проблемы. M., URSS, 384 c.

3. Ван Ж., Стародумова Е.А. 2018. Частица «БЫ» в предложениях с условными отношениями. Научный диалог, 5: 30-40.

4. Виноградов В.В. 2001. Русский язык (Грамматическое учение о слове). Под. ред. Г.А. Золотовой. М., Рус. яз., 720 с.

5. Винокур Т.Г. 2016. Говорящий и слушающий: Варианты речевого поведения. М., Наука, $171 \mathrm{c}$.

6. Вольф Е.М. 2010. Функциональная семантика оценки. М., Либроком, 278 с.

7. Катермина В.В. 2015. Человеческий фактор в языке. Человек. Культура. Образование. 2 (16): $222-232$.

8. Колмогорова А.В. 2016. Методология коммуникативных исследований в лингвистике. Красноярск, Изд-во СФУ, 102 с.

9. Лакофф Дж. 1988. Мышление в зеркале классификаторов. В кн. Новое в зарубежной лингвистике. Вып. 23. Когнитивные аспекты языка. Под ред. В.В. Петрова, В.И. Герасимова. М., Прогресс: 12-51.

10. Ломтев Т.П. 2020. Предложение и его грамматические категории. М., Изд. URSS, 200 с.

11. Мелехова Л.А., Сергиевская Л.А. 2019. Коннотативные смыслы высказывания в грамматической концепции П.А. Леканта и современной русистике. В кн. Рациональное и эмоциональное в русском языке. Сборник трудов Международной научной конференции, посвященной памяти профессора П.А. Леканта, г. Москва, 19 ноября 2019 г. Под ред. Н.Б. Самсонова. Москва, ИИУ МГОУ: 20-24.

12. Нагорный И.А. 2019. Грамматико-коммуникативные функции частиц в речевой сфере. Научные ведомости Белгородского государственного университета. Серия: Гуманитарные науки, 38 (3): $369-378$.

13. Отношение к говорящему в семантике грамматических категорий. 2020. Под ред. В.В. Казаковской, М.Д. Воейковой. Серия: Проблемы функциональной грамматики. М., Издательский Дом ЯСК, 285 с.

14. Шведова Н.Ю. 2003. Очерки по синтаксису русской разговорной речи. М., Азбуковник, $377 \mathrm{c}$.

15. Перехвальская Е.В. 2020. Этнолингвистика. М., Издательство Юрайт, 351 с. URL: https://urait.ru/bcode/450613 (дата обращения: 05.10.2020).

16. Börjesson K. 2016. The semantics-pragmatics interface: The role of speaker intentions and the nature of implicit meaning aspects/. In: La sémantique linguistique en vision périphérique. Dans Langages, 1 (201): 15-32

17. Depraetere I. 2015. Categorization principles of modal meaning categories: a critical assessment. Anglophonia. French Journal of English Linguistics. Vol.19. Modalisationa posteriori. P. 78-88.

18. Hans K. 2019. Epistemic Specificity from a Communication-Theoretic Perspective. Journal of Semantics. Vol. 36. Iss. 1: 1-51.

19. Lakoff G. 1975. Pragmatics in natural logic. In: Formal semantics of natural lfnguage. Ed. E.L. Keenan. Los Angeles: 253-286.

20. Schwarz F., Tiemann S. 2017. Presupposition Projection in Online Processing. Journal of Semantics. Vol. 34. Iss. 1: 61-106.

21. Yu A.D. 2017. A modal account of propositions. Dialectica. Vol. 71, Iss. 4: 463-488.

\section{References}

1. Arutyunova N.D., Bulygina T.V., Kibrik A.A. 1992. Chelovecheskiy faktor v yazyke. Kommunikatsiya, modal'nost', deyksis [The human factor in language. Communication, modality, deixis]. Ed. T.V. Bulygina. M., Publ. Nauka, 280 p.

2. Arutyunova N.D. 2019. Predlozhenie i ego smysl. Logiko-semanticheskie problemy [The proposal and its meaning. Logical-semantic problems]. M., Publ. URSS, 384 p. 
3. Van Zh., Starodumova E.A. 2018. Chastitsa «BY» v predlozheniyakh s uslovnymi otnosheniyami [Particle "BY" in sentences with conditional relationships]. Nauchnyy Dialog, 5: 30-40.

4. Vinogradov V.V. 2001. Russkiy yazyk (Grammaticheskoe uchenie o slove) [Russian language (Grammatical teaching about the word)]. Ed. G.A. Zolotova. M., Publ. Rus. yaz., 720 p.

5. Vinokur T.G. 2016. Govoryashchiy i slushayushchiy: Varianty rechevogo povedeniya [Speaker and Listener: Variants of Speech Behavior]. M., Publ. Nauka, 171 p.

6. Vol'f E.M. 2010. Funktsional'naya semantika otsenki [Functional Semantics of Evaluation]. M., Publ. Librokom, 278 p.

7. Katermina V.V. 2015. Chelovecheskiy faktor v yazyke [The human factor in the language]. Human. Culture. Education. 2 (16): 222-232.

8. Kolmogorova A.V. 2016. Metodologiya kommunikativnykh issledovaniy v lingvistike [Methodology of Communication Research in Linguistics]. Krasnoyarsk, Publ. SFU, 102 p.

9. Lakoff Dzh. 1988. Myshlenie v zerkale klassifikatorov [Thinking in the mirror of classifiers]. In: Novoe $\mathrm{v}$ zarubezhnoy lingvistike [New in foreign linguistics]. Iss. 23. Kognitivnye aspekty yazyka [Cognitive aspects of language]. Eds. V.V. Petrov, V.I. Gerasimov. M., Publ. Progress: 12-51.

10. Lomtev T.P. 2020. Predlozhenie i ego grammaticheskie kategorii [Sentence and its grammatical categories]. M., Publ. URSS, 200 p.

11. Melekhova L.A., Sergievskaya L.A. 2019. Konnotativnye smysly vyskazyvaniya v grammaticheskoy kontseptsii P.A. Lekanta i sovremennoy rusistike [Connotative meanings of a statement in the grammatical concept of P.A. Lecant and modern Russian studies]. In: Ratsional'noe i emotsional'noe v russkom yazyke [Rational and Emotional in Russian]. Sbornik trudov Mezhdunarodnoy nauchnoy konferentsii, posvyashchennoy pamyati professora P. A. Lekanta, g. Moskva, 19 noyabrya 2019 g. Ed. N.B. Samsonov. Moskva, Publ. IIU MGOU: 20-24.

12. Nagornyy I.A. 2019. Grammatiko-kommunikativnye funktsii chastits v rechevoy sfere [Grammatical and communicative functions of particles in the speech sphere]. Scientific bulletin of Belgorod State University. Humanities Sciences, 38 (3): 369-378.

13. Otnoshenie $\mathrm{k}$ govoryashchemu $\mathrm{v}$ semantike grammaticheskikh kategoriy [The relation to the speaker in the semantics of grammatical categories]. 2020. Eds. V.V. Kazakovskaya, M.D. Voeykova. Seriya: Problemy funktsional'noy grammatiki [Problems of functional grammar]. M., Publ. YaSK, 285 p.

14. Shvedova N.Yu. 2003. Ocherki po sintaksisu russkoy razgovornoy rechi [Essays on the syntax of Russian colloquial speech]. M., Publ. Azbukovnik, 377 p.

15. Perekhval'skaya E.V. 2020. Etnolingvistika [Ethnolinguistics.]. M., Publ. Yurayt, 351 p. Available at: https://urait.ru/bcode/450613 (accessed: 05.10.2020).

16. Börjesson K. 2016. The semantics-pragmatics interface: The role of speaker intentions and the nature of implicit meaning aspects/. In: La sémantique linguistique en vision périphérique. Dans Langages, 1 (201): 15-32.

17. Depraetere I. 2015. Categorization principles of modal meaning categories: a critical assessment. Anglophonia. French Journal of English Linguistics. Vol.19. Modalisationa posteriori. P. 78-88.

18. Hans K. 2019. Epistemic Specificity from a Communication-Theoretic Perspective. Journal of Semantics. Vol. 36. Iss. 1: 1-51.

19. Lakoff G. 1975. Pragmatics in natural logic. In: Formal semantics of natural lfnguage. Ed. E.L. Keenan. Los Angeles: 253-286.

20. Schwarz F., Tiemann S. 2017. Presupposition Projection in Online Processing. Journal of Semantics. Vol. 34. Iss. 1: 61-106.

21. Yu A.D. 2017. A modal account of propositions. Dialectica. Vol. 71, Iss. 4: 463-488.

\section{ИНФОРМАЦИЯ ОБ АВТОРЕ}

Нагорный Игорь Анатольевич, доктор филологических наук, профессор, профессор института иностранных языков Цзилиньского университета, г. Чанчунь, Китайская Народная Республика

\section{INFORMATION ABOUT THE AUTHOR}

Igor A. Nagorny, Doctor of Philology, Professor, Professor of the Institute of Foreign Languages, Jilin University, Changchun, People's Republic of China 